reduce the very slender and congested bowel. The absence of fluid in both sacs was perhaps rather unusual and necessitated an extra amount of care in opening them.

\section{LEICESTER INFIRMARY.}

a CASE OF DECIDUOMa MaLIGNUM.

(Under the care of Mr. H. J. BLAKESLEY and Dr. R. SEvestRe.)

OASES of deciduoma malignum are of sufficient rarity to make it desirable that they should be published, especially when the post-mortem and histological records are complete. The following case illustrates well all the typical features of the disease.

A married woman, aged 31 years, was admitted into the Leicester Infirmary in October, 1901. She stated that eight months before admission she had passed through a normal confinement, being attended by a midwife, and that one month afterwards menstruation occurred naturally. weeks after her confinement she began to lose blood per vaginam and continued to do so up to the date of admission except for short periods when blood-stained fluid was observed. She had been rapidly failing in health and losing flesh, especially during the last three months, and had complained of severe cough for about three weeks, with dyspncea of late on the slightest exertion. Four or five days previously to admission she had noticed two swellings on the left side of the vulva. The patient's history was as follows. She began to menstruate at the age of 14 years and was married at 21 zears. She had had seven children, three of whom were still-born; she had had no miscarriages. On admission her condition was that of an emaciated and anæmic woman with flushed cheeks and frequent short dry cough and raised temperature. She did not complain of any pain. On examination of the heart a systolic murmur was heard which from its position and character was believed to be hæmic in origin. Coarse moist sounds were heard over the lungs which were most marked at their bases. On abdominal examination nothing of an abnormal character was found. On vaginal examination an oval, smooth, non-fluctuating swelling of a deep purple colour and of about the size of a walnut was found situated on the inner aspect of the posterior half of the left labium majus ; immediately internal to this, but separate from it, was a smaller swelling of a similar character, with superficial ulceration on its surface. The cervix was in the middle line and was patulous and torn on the left side. Bimanually the uterus was felt to be enlarged and retroverted but moveable. The catheter specimen of the urine was found to be free from albumin and sugar. The case was believed to be one of retained products of conception.

On the third day after admission the patient was anæsthetised with ether, the cervix was drawn down by a vulsellum, and after Nos. 12, 13, and 14 Hegar's dilators had been passed the finger was introduced. A lobulated, firm, sessile mass was felt occupying the cavity of the uterus, being attached to the left upper half of the organ; by means of the finger and curette the greater part of the mass was removed piecemeal. The fragments removed had the appearance of hardened placental tissue. The amount of blood lost during this procedure was very small in quantity and the uterus contracted firmly. On incising the mucous membrane over the swellings in the vulva their contents readily shelled out and consisted of blood-clot with firmer strands running through them. The patient rallied well after the operation; there was no further hæmorrhage, only a slight blood-stained watery discharge. Her general condition appeared to improve after the operation for a few days, but very soon the lung symptoms became more severe the temperature ranged between $101^{\circ}$ and $102^{\circ} \mathrm{F}$, but there were no rigors or other evidence of septic infection, and she died on the seventeenth day after admission.

Portions of the material removed by the curette were sent to the Clinical Research Association and the report received was to the effect that it was a case of deciduoma malignum.

Necropsy. - At the post-mortem examination the uterus was found to be larger than normal. On its anterior surface between the middle line and the upper part of the left broad ligament were two tuberosities placed almost vertically, but quite separate from each other, which were clearly portions of growth. Each tuberosity had a smooth and rounded out line; the lower one, the larger of the two, was inclined to be conical in shape, with a base of about one inch in diameter. In colour they were dark red. To the touch they were softer than the surrounding parts but did not give the sense of fluctuation; the peritoneum covering them was smooth and bright. The rest of the external aspect of the uterus presented a normal appearance. The uterus was opened by a vertical incision on its anterior aspect. Its cavity presented the appearance that would be expected after curettage except in the part beneath the tuberosities, where the surface was irregular and of a dark-red colour, this clearly being a portion of the growth that the curette had not reached. On the left labium majus there were two raw surfaces from which growths had been removed at the operation. Both lungs were studded on their surfaces with secondary growths which in outline were round and of a dark-red colour; these growths were more numerous at the base than at the apex, the largest being of about the size of a walnut. On section of one of these secondary nodules a reticulated appearance was seen with what appeared to be blood-clot in the spaces. It was not found possible to make a complete post-mortem examination but no evidence of growth was observed in other organs.

On examining a microscopic section of the uterus the margin of the growth was seen to be made of masses of cells forcing their way into the surrounding tissue. These cells were not arranged in alveoli. Internally to the growing margin were seen the remains of the cells of the normal tissue with cells of the new growth and much extravasated blood; this gradually merged into a part where no definite structure could be made out but which appeared to consist of blood-clot and broken-down tissue. On further examining the growing margin two varieties of cells were to be seen. The greater number of cells which had no stroma between them were larger and round or ovoid, with deeply-staining nuclei; in some the nucleus had contracted to one side, leaving a vacuole. Besides these single cells there were here and there masses of protoplasm containing a number of nuclei, the so-called syncytium; on closer examination, however, these multi-nucleated masses suggested that they were made up of numbers of large ovoid cells fused together. There was no appearance of new fibrous tissue. Immediately behind the growing margin a section showed patches of extravasated blood mixed with the tumour cells and it was by no means easy to say what relation the blood-vessels had to the cells of the tumour.

Remarks by Mr. BLAKESLEY and Dr. SEvestRe. - This case illustrates the chief symptoms of the disease, in the first place following on pregnancy, in a multipara, the early appearance and continuance of hæmorrhage, the rapid wasting with hectic temperature, and signs pointing to extensive disease of the lungs. Most of the above symptoms and signs are such as are common to cases of retained products of conception and, as a rule, the diagnosis is made from microscopic section of a portion of the growth after removal. It further illustrates the extreme malignancy of this disease, death occurring seven months after the history of its commencement. Although the signs and symptoms of this disease are sufficiently clear for it to have a distinct clinical entity the same cannot be said of its pathological character and there is much diversity of opinion as to whether it should be classed among the carcinomata or sarcomata. The distribution of the secondary growths by the blood-stream and some of the features noticed in the description of the microscopic section appear to support the view, which is generally held, that these tumours ought to be classed among the sarcomata.

Several views are held in regard to the origin of these tumours; by some it is thought that they arise in the uterine tissues and are modifed by pregnancy or its results, by others that they arise in decidual tissues. It is important to remember that these tumours always occur within a few weeks or months after abortion or delivery at term or not infrequently after the condition called hydatidiform mole. If it arises in tissues not connected with the decidua of pregnancy it is curious that its effects are noticed after delivery and not before. As regards the structures in the decidua from which the tumour may arise there is mucl diversity of opinion and this point is not likely to be settled till more is known of the tissues in which the placenta arises. By some the growth is considered to be a carcinoma and this view is based on the resemblance of cells to the syncytium of the chorionic villi, the syncytium being considered to be epiblastic in origin. Whatever may be the ultimate views held as to its origin, it is at present clear that in regard to 
rapidity of growth, dissemination, and the short time it lakes to destroy life, it must be considered as one of the most malignant tumours known.

References.-Hart and Barbour : fifth edition; Allbutt: System; of Aynzcology; Journal of Pathology, vol. v., p. 358 .

\section{Iftedical Surreties.}

\section{OPHTHALMOLOGICAL SOCIETY.}

\section{Secondary Carcinoma of the Eye. -Leprous Ulcer of the Cornea.-A Doubtful Case of Atropine Poisoning.-- Bilateral Congenital Miorophthalmos. - 'olloid Uegenera- tion of the Conjunotiva. - Exhibition of cases and Card Specimens.}

AN ordinary meeting of this society was held on June 12th, Dr. David LiTrue, the President, being in the chair.

Dr. W. C. RockLIFFE (Hull) read notes of the termination of his case of Secondary Carcinoma of the Eye exhibited to the society in July, 1901. The left eye was excised on July 12th, 1901, and the specimen and slide, kindly mounted by Mr. W. T. Lister, then pathologist to the Royal London Ophthalmic Hospital, showed the cornea to be healthy with a rather shallow anterior chamber, the angle being narrowed but not closed, the lens being apparently healthy and in situ, and the vitreous entirely absorbed. Situated at the posterior part and extending from the optic nerve to the ciliary processes was a large flat unpigmented tumour (which at the optic nerve appeared to be about from two to three millimetres in thickness and gradually tapered as it advanced) originating in the choroid. The retina was completely detached. Microscopically the growth was limited to the choroid and consisted of numerous round cells grouped together with connective tissue. Hardly any pigment cells were discernible except in the anterior half of the choroid where they lay internally to the new growth and from which they appeared to be entirely free. The vessels were new and were entirely confined to the connective tissue network. The optic nerve also had several tumour cells scattered among its fibres and the sclerotic at the posterior portion was sparsely infiltrated with the same. There were several areas of degeneration in this growth. On July 30th vision in the right eye was $\frac{6}{18}$. Detachment of the retina was increased and there was shooting pain round the eyeball. On August 10th there was an attack of pleurisy from which the patient appeared to recover, but later there were stiffness. pain, and swelling in the left leg. The right optic disc was congested and the entire retina was swollen and further detached. The patient died on Nov. 30th, the most troublesome symptoms having been vomiting and paroxysmal cough. Vision had gradually deteriorated but there was little or no pain in the head or in the eye. The patient had also continual constipation and was comatose during the last 48 hours. It appeared that secondary carcinoma of the eye more commonly followed carcinoma of the breast, affecting females rather than males between the ages of 40 and 60 years. The tumour was flat and consequently tension was not increased. Duration of life, though varying after the first appearance of eye symptoms, did not usually exceed two years.-Mr. W. T. HoLMES SPICER cited a case in which metastasis occurred in one eye 30 months after removal of the breast for cancer. Two separate detachments of the retina were noted; the appearance varied but the tension was not raised. Nutrition being good the eye was removed a few weeks ago and flat scirrbous growths were found opposite the detachments. It was a difficult point to decide whether the eye should be removed in these cases. -Mr. A. HILL GRIFFITH said that these flat wafer-like growths were usually due to carcinoma of the choroid following a primary growth in the breast. He thought, however, that sarcoma of the choroid if seen in an early stage would have a similar appearance and he cited a case in which he had removed an eye having this appearance and had found the growth to be sarcoma.-Mr. C. DeVEREUX Marshall said that the tendency of carcinoma was to spread laterally, whereas sarcoma assumed a mushroom shape, but in the early stage the resemblance was very close. Carcinoma occurred secondarily in the eye probably more often than had been supposed, and since attention had been directed to the matter several cases had been recorded.
In auvanced cases of cancer defects in the eye were either overlooked or not paid much attention to.

Dr. RoCKLIFFE then read notes of a case of Leprous Ulcer of the Cornea in a young man, a native of the West Indies. He exhibited prints of skiagrams showing the various bone changes takiog place in this disease. He also referred to the obstinacy of the corneal ulcer to treatment in spite of frequent galvano-cauterisation, \&c.

Dr. RockLIFFE also read notes of a case of Supposed Death from Atropive Poisoning. The patient (one of four survivors of a family of 12 ) was a very delicate-looking child, aged 10 months, who had suffered from convulsions most of this time. He first of all put three drops of a 1 per cent. solution of atropine iu the eyes which did not dilate the pupils fully. More atropine was applied, but during the 30 hours which elapsed from the first using of the atropine only seven drops were used, one-seventeenth of a grain. The temperature rose to $1056^{\circ} \mathrm{F}$. The pulse was uocountable and the respirations were 72 ; the skin was red and the lips had a quantity of mucus about them. In this state the child died. Nothing abnormal was found post mortem.

Dr. A. BronNer (Bradford) read notes on Two Families with Bilateral Congenital Microphthalmos and Cataract. In one case the father and four out of eight children were affected; these were numbers $3,5,6$, and 8 . The eyes of the mother were normal. There was no consanguinity nor was there any history of syphilis. In the other series the mother and all the four children were similarly affected. The paternity of the children was somewhat uncertain. The maternal grandmother was said to have had similar eyes.-Dr. D. ARGYLL RoBertson had once operated on a boy with this condition, the father having similar eyes and having previonsly undergone a successful operation for the removal of his cataract. In both fair vision resulted, though the eye was only two-thirds of the normal size.-Dr. P. H. MULEs thought that in such cases there was usually congenital syphilis. He referred to two cases of the kind. Mr. PRIESTLEY SMITH said that there was no hard-and-fast line to be drawn between the small eye and the microph. thalmic one. If the diminished size was very marked probably the lens was small and opaque, but if the lens was clear and full sized then glaucoma was almost certain to result. On the whole he thought that the subjects of the former variety were less liable to become blind than were those of the latter. He had attended a father and daughter with small eyes, the cornea measuring only $10 \frac{1}{2}$ millimetres. Both had glaucoma. - Mr. W. A. Frost thought that those having a congenital coloboma were less liable to glaucoma. Professor FUCHS (Vienna) had seen but one case : a man who had lost an eye from acute blenorrhoea had a child who suffered from microphthalmos on the same side.

Major H. HerberT, I.M.S., described a case of Colloid Degeneration of the Conjunctiva. This affection had been wrongly named "amyloid" or "hyalin" degeneration. Similar changes had been found rarely in the skin of old people and had been correctly described by dermatologists as "colloid" degeneration. The ocular conjunctivæe only were affected, the palpebral portions being occupitd by scar tissue from old trachoma; a swollen translucent fold overhung the upper third of each cornea. The change consisted mainly in a swelling and breaking up and rearrangement of white connective tissue fibres (collagenous) and also of elastic fibres. In the deeper tissues the new material became moulded into rounded and elliptical blocks, probably by constant stretching and movement of the fold. In the centre of many of these blocks plasma cells were inclosed, more rarely smaller masses of colloid or masses of blood pigment. Other blocks with central cavities represented the remains of blood-vessels. On the other hand, other blood-vessels had undergone rarefaction of their walls, instead of colloid thickening and occlusion. Many of the blocks had connective tissue cells closely applied to them. Special staining with acid fuchsin and acid orcein showed imbedded in many of the blocks the remains of white connective tissue fibres and in others elastic fibres. But the change was so advanced in the tissue examined that it was only close beneath the epithelium, in a layer of adenoid tissue, that the transition from collagen to colloid could be followed. In this layer a few true hyalin balls were to be found, and both here and in the deeper tissues many golden pigment granules the remains of hæmorrhages. Here and there some of the deeper colloid had coalesced into large and rather firm opaque waxy masses two or three millimetres 